The following paper posted here is not the official IEEE published version. The final published version of this paper can be found in the Proceedings of the IEEE Conference on Industrial Electronics and Applications (2nd : 2007 : Harbin, China):pp.96-101

Copyright (c) 2007 IEEE.

Personal use of this material is permitted. However, permission to reprint/republish this material for advertising or promotional purposes or for creating new collective works for resale or redistribution to servers or lists, or to reuse any copyrighted component of this work in other works must be obtained from the IEEE. 


\title{
Detection and Remediation of Switch Faults on a Fault Tolerant Permanent Magnet Motor Drive with Redundancy
}

\author{
Jingwei Zhu*, Nesimi Ertugrul, and Wen Liang Soong \\ School of Electrical and Electronic Engineering \\ The University of Adelaide, Adelaide, Australia, SA 5005 \\ *Email: jingwei@eleceng.adelaide.edu.au
}

\begin{abstract}
Fault-tolerant motor drives are becoming more important in safety critical applications. Using a special motor design and an appropriate inverter topology, brushless permanent magnet $\mathrm{AC}$ motor drives can have a fault-tolerant capability. This paper considers a dual motor drive system on a common shaft to introduce redundancy. The paper provides a systematic classification for the potential electrical faults which may occur in a real motor drive. In the paper, the switch and winding short circuit fault detection and identification methods are studied and experimental results are presented. In addition, the effects of switch faults on the phase currents and output torque are discussed, and remedial strategies for these faults are proposed. Furthermore, it was also demonstrated using simulation results that the proposed remedial strategies can compensate for the loss of torque due to the switch faults and can keep the peak-to-peak torque ripple factor comparable to healthy operation of the drive.
\end{abstract}

\section{INTRODUCTION}

Safety critical motor drive systems are becoming more important in many areas such as aerospace, transportation, medical and military applications, and nuclear power plants. In these application systems, any failure of motor drives may result in loss of property and human life. Therefore, the motor drives utilized in safety critical applications must be fault tolerant, and they should continue to operate even in the presence of one or more faults.

A number of studies have been reported in the literature which investigates fault tolerant motor drives. Switched reluctance motors (SRM) are inherently fault tolerant [1]. However, higher acoustic noise and lower torque density of such motors limit their applications. Using special design techniques, brushless permanent magnet (PM) motors can be made fault tolerant [2-4]. A comparative study carried out in [5] has suggested that both SRM and brushless PM motors have a similar degree of fault tolerance, while the brushless PM motor drives have a higher torque density and lower acoustic noise than SRM drives. In addition, in order to provide redundancy, a dual fault-tolerant brushless PM motor drive system was proposed in [6]. The performance investigation of this type of motor drive was also provided in [7].

The potential faults in a brushless PM motor drive can be classified under a number of groups: winding open-circuit, winding short-circuit, switch open-circuit, switch short-circuit, power supply fault, position sensor fault and combinations of the above faults. Amongst these fault groups, the switch faults (also known as the inverter faults) are the most common fault, which must be considered in the fault tolerant motor drive. Fault detection and isolation methods on a PWM inverter was presented in [8-9]. In addition, inverter faults and control of brushless PM motor drives were studied in [10] and fault tolerant strategies under switch faults were reported in [11].

It can be concluded from the literature survey that the existing fault analysis and investigations are mainly concentrated on brushless PM motors with three-phase starconnected windings or using a single motor module with three isolated windings. In addition, in the previous studies, the inverter fault detection methods commonly utilize multiple voltage sensors to obtain the on-state voltage of a switch which may increase the cost of the drive significantly.

It should be noted here that although a single motor faulttolerant drive system may be sufficient in various critical applications, it does not offer any redundancy if the entire single motor drive is out of operation [12]. Furthermore, the operation with inverter faults in such a single motor drive results in large output torque ripple.

Therefore, this paper considers a dual motor drive system on a common shaft to introduce redundancy. The paper provides a systematic classification of all electrical faults in a dual fault tolerant PMAC motor drive. A switch fault detection method is presented. The effect of switch faults on the phase current and output torque are studied and remedial strategies are proposed. Finally, the experimental test arrangement and motor controller based on a microcontroller are introduced.

\section{FAUlT ClassificAtion}

\section{A. Motor Configuration}

In order to produce a fault-tolerant brushless PM motor, it is important to minimize or eliminate the electrical, magnetic and thermal coupling between the motor windings [2]. Thus, a failure in one winding will not affect the operation of the remaining windings. This can be achieved by physically separating the motor windings and driving each winding using a separate single-phase H-bridge inverter circuit.

Fig. 1 shows one of the modules of the three-phase faulttolerant brushless PM AC motor winding configuration 
utilized in this paper. As can be seen in the figure, each phase winding occupies two different slots around a single tooth. In order to improve the redundancy, two motor modules are connected to a common shaft. Fig. 2 illustrates the measured back-EMF waveforms of one of the phases of the motor under test. In the simulation studies of the drive system, the backEMFs of the motor windings are modeled as ideal sine waveforms, and sinusoidal current control is implemented in the drive system.

\section{B. Fault Classification}

As stated previously, a number of faults may occur in a brushless PMAC motor drive. The potential electrical faults can be classified into three main groups: short-circuit faults, open-circuit faults and auxiliary circuit or device related faults.

The short-circuit and open-circuit faults in the drive are identified and defined in the paper using the following approach:

- All possible inverter faults are defined using numbers (see Fig. 3 for short-circuit faults),

- $\quad$ Short-circuit and open-circuit faults are abbreviated by $\mathrm{SC}$ and $\mathrm{OC}$ respectively,

- The letters A, B, C, D, E, and F are utilized to define the fault location in the six H-bridge inverters.

Using this approach, 11 short-circuit and 10 open-circuit faults of a single phase of the motor drive can be identified as given in Table 1 and Table 2 for Phase A. The tables also indicate the possible remedial strategies for a given fault, which are named as "unipolar operation" and "disabling phase".

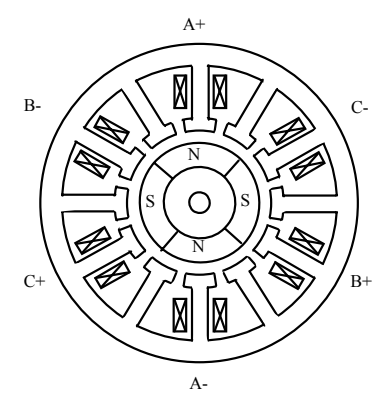

Fig. 1. Winding arrangement of the 4-pole three-phase fault-tolerant brushless PMAC motor.

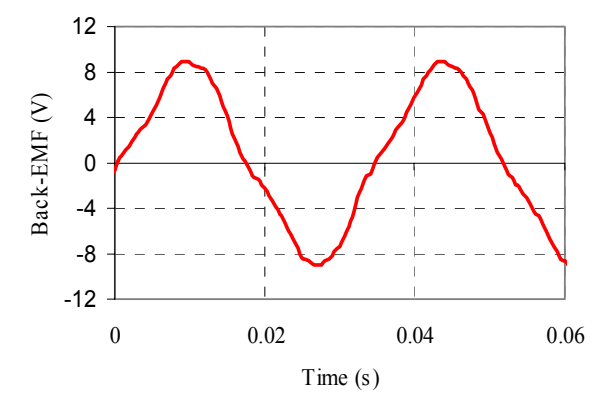

Fig. 2. Measured back-EMF waveform of the test motor at $870 \mathrm{rpm}$.

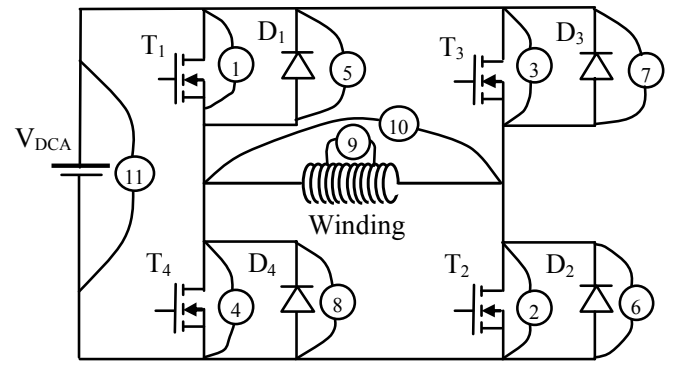

Fig. 3. Locations of possible H-bridge inverter short-circuit faults.

TABLE I

POSSIBLE SHORT-CIRCUIT FAULTS IN PHASE A AND CORRESPONDING POSSIBLE REMEDIAL STRATEGY

\begin{tabular}{|l|l|l|}
\hline \multicolumn{1}{|c|}{ Fault name } & \multicolumn{1}{c|}{ Fault description } & \multicolumn{1}{c|}{ Remedial strategies } \\
\hline SCA1 & Switch T1 & Disabling phase \\
\hline SCA2 & Switch T2 & Disabling phase \\
\hline SCA3 & Switch T3 & Disabling phase \\
\hline SCA4 & Switch T4 & Disabling phase \\
\hline SCA5 & Diode D1 & Disabling phase \\
\hline SCA6 & Diode D2 & Disabling phase \\
\hline SCA7 & Diode D3 & Disabling phase \\
\hline SCA8 & Diode D4 & Disabling phase \\
\hline SCA9 & Partial winding & Disabling phase \\
\hline SCA10 & Full winding & Disabling phase \\
\hline SCA11 & Power short & Disabling phase \\
\hline
\end{tabular}

TABLE II

POSSIBLE OPEN-CIRCUIT FAULTS IN PHASE A AND CORRESPONDING POSSIBLE REMEDIAL STRATEGY

\begin{tabular}{|l|l|l|}
\hline \multicolumn{1}{|c|}{ Fault name } & \multicolumn{1}{|c|}{ Fault description } & \multicolumn{1}{c|}{ Remedial strategies } \\
\hline OCA1 & Switch T1 & Unipolar operation \\
\hline OCA2 & Switch T2 & Unipolar operation \\
\hline OCA3 & Switch T3 & Unipolar operation \\
\hline OCA4 & Switch T4 & Unipolar operation \\
\hline OCA5 & Diode D1 & Unipolar operation \\
\hline OCA6 & Diode D2 & Unipolar operation \\
\hline OCA7 & Diode D3 & Unipolar operation \\
\hline OCA8 & Diode D4 & Unipolar operation \\
\hline OCA9 & Winding open-circuit & Disabling phase \\
\hline OCA10 & Power open & Disabling phase \\
\hline
\end{tabular}

The auxiliary circuit or device related faults in the drive include power supply fault, rotor position sensor fault, current sensor fault and controller fault. In this paper, a separate power supply is considered for each phase, and the rotor position estimation algorithm is developed using the phase voltage and current [13].

\section{FAULT DETECTION AND IDENTIFICATION}

\section{A. $\quad$ Fault Detection}

Although all the faults defined in the previous section might occur in the motor drive system, this paper considers the detection and identification methods for switch and winding faults only.

The winding open-circuit fault is the most common fault, and can be detected by the phase current sensor. This fault can be identified when the phase voltage equals to the voltage of power supply while the phase current is zero.

The winding short-circuit fault is one of the most critical faults in the motor drive. Such a fault can cause over-currents in the motor winding, which needs to be detected timely and a 
suitable remedial strategy needs to be adopted to prevent further damage to the motor windings.

The switch short-circuit fault is also a serious fault as it can produce a shoot-through fault in the inverter when the switch on the same leg is turned on.

It can be noted here that, if the switches of the inverter accommodate built-in free wheeling diodes, the diode shortcircuit fault can be considered like a switch short-circuit fault.

As indicated previously, switch fault detection and isolation methods are studied in [8-11]. The existing inverter fault detection methods however, utilize voltage sensors to determine the on-state voltage of the switch. In a conventional wye-connected three-phase PM motor drive, voltage sensing method requires six voltage sensors. In a fault tolerant motor drive using the H-bridge inverter circuit however, this method needs 12 voltage sensors and associated signal conditioning and sampling circuits, which can increase the cost significantly and add significant burden to the processing power of the motor controller. Another disadvantage of the voltage sensing method is that the gate trigger signal of switches is removed by the controller, which requires additional processing time hence introduces further delays. This paper eliminates the voltage sensing method and adopts a fault detection circuit at the switch driver level for each inverter switch.

In this study, separate low and high side MOSFET drivers (IR2121 and IR2125) with the current sensing function are utilized. Fig. 4 illustrates switch $\mathrm{T}_{1}$ and its driver circuit. The current sensing features of the driver circuits uses a timing circuit (via the ERR pin as seen in Fig.4) to program the time between over-current detection and latch shutdown. If there is no gate signal in the circuit, the $\mathrm{V}_{\mathrm{CS}}$ pin is zero. If there is a gate signal however, the switch T1 turns on and the diode D2 is forward biased. Hence $\mathrm{V}_{\mathrm{CS}}$ can be given as

$$
V_{C S}=\frac{R_{4}}{R_{3}+R_{4}}\left(V_{D}+V_{D S}\right)
$$

where, $\mathrm{V}_{\mathrm{DS}}$ is the turn-on voltage of the MOSFET switch, which is proportional to the switch current $\mathrm{I}_{\mathrm{D}}$. If an overcurrent flows through the device, $\mathrm{V}_{\mathrm{CS}}$ exceeds the threshold value of driver (that is about $230 \mathrm{mV}$ ). Then the protection circuit is triggered and the gate voltage $\mathrm{V}_{\mathrm{G}}$ becomes zero to turn the switch off, and the pin ERR goes high to indicate the fault at the same time.

When the switch $\mathrm{T} 1$ has an open-circuit fault however, the pin $\mathrm{V}_{\mathrm{CS}}$ voltage is given by

$$
V_{C S}=\frac{R_{4}}{R_{2}+R_{3}+R_{4}} \cdot V_{G}
$$

which exceeds the threshold voltage and the gate driver of the switch is turned off as before.

The experimental results of the fault detection function in the switch drivers of the H-bridge inverter circuit are provided in Fig. 5, Fig. 6 and Fig. 7, which illustrate the healthy operation, over current operation and switch opencircuit fault operation respectively. These results show that the driver circuit can generate the ERR fault signal to the motor controller when an over-current fault or switch opencircuit fault occurs in the motor drive.

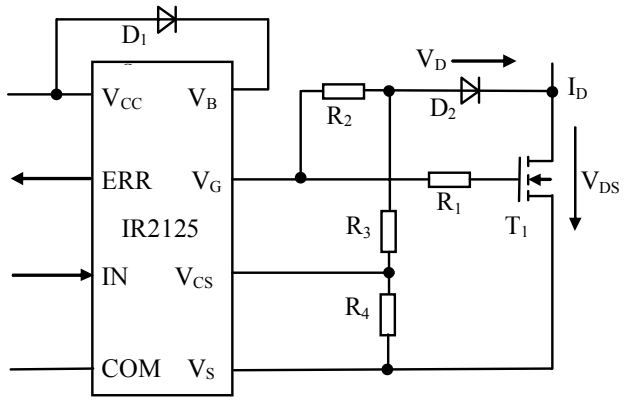

Fig. 4. A high side switch and its driver circuit with the fault detection function

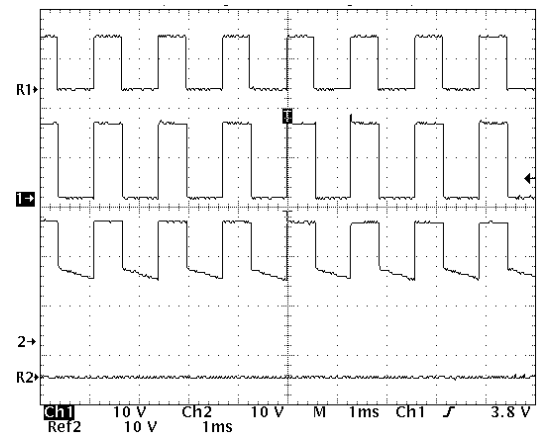

Fig. 5. The MOSFET driver waveforms in healthy operation, from top to bottom: drive input signal, T2 driver output signal, $\mathrm{T} 1$ driver output signal and T1 driver ERR signal.

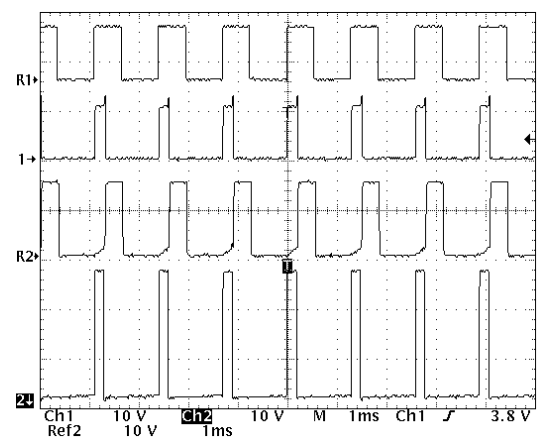

Fig. 6. MOSFET driver waveforms in over-current operation, from top to bottom: driver input signal, T2 driver output signal; $\mathrm{T} 2$ drive ERR signal and T1 driver output signal.

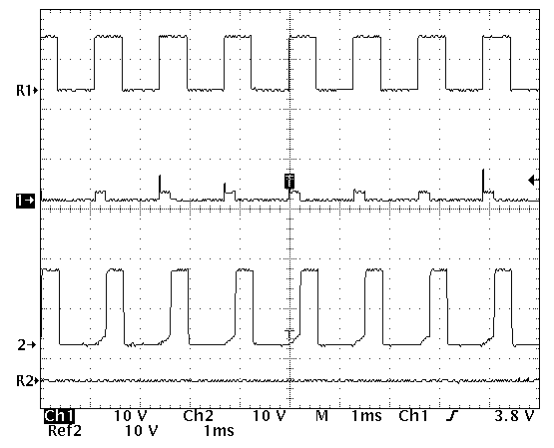

Fig. 7. MOSFET drive waveforms in T2 open-circuit fault operation, from top to bottom: drive input signal; T2 driver output signal; T2 driver ERR signal and T1 driver ERR signal. 


\section{B. $\quad$ Fault Identification}

As stated earlier, the over-current fault may be the result of a switch short-circuit fault or a winding short-circuit fault. In addition, the switch open-circuit fault and some electrical disturbances may also generate the ERR fault signal. Therefore, to identify the type of faults accurately, a fault identification algorithm is required in the controller for each switch. The principles of the $\mathrm{T} 1$ and $\mathrm{T} 2$ fault identification algorithm (that is related to the inverter circuit Fig. 3) is given in Fig. 8. Using this fault identification algorithm, the T1 open-circuit fault, T4 short circuit fault and the winding shortcircuit fault can be identified. Similarly, the T1 short-circuit fault can be identified by the T4 fault identification algorithm.

\section{REMEDIATION OF SWITCH FAULTS}

\section{A. Remediation of Switch Open-Circuit Fault}

As can be seen in the inverter circuit, if one of the inverter switches has an open-circuit fault, the relevant $\mathrm{H}$-bridge inverter circuit can operate in unidirectional conduction mode. For example, referring to Fig. 3, if the switch T1 has an opencircuit fault, the current in phase A can still flow through the switches T3 and T4.

Fig. 9 illustrates the simulation waveforms of a phase current and the output torque of the motor drive when the switch $\mathrm{T} 1$ open circuit fault occurs at $\mathrm{t}=3.0 \mathrm{~s}$. As can be seen in these results, if no remedial strategy is adopted, the average output torque will be decreased. At the same time, the output torque ripple factor (peak-to-peak torque ripple) is found to be much higher $(41.8 \%)$ than in healthy operation $(7.3 \%)$. Such an increase in the torque ripple can result in high vibration and noise in the motor drive. Therefore, a remedial strategy should be considered after the switch open-circuit fault is detected.

The primary target of the dual fault tolerant motor drive as considered in this paper is to provide rated (or near rated) torque even under faulted operation. Since the output torque in the motor drive is proportional to the phase current, one possible remedial strategy is to increase the current in the healthy phases. For example, if one of the switches in a dual three-phase motor drive has an open-circuit fault and the corresponding inverter works in unipolar operation mode, the current of the healthy phases should be 12/11 times of the rated current to compensate the torque loss due to the fault. However, this method increases the torque ripple significantly.

In this study, two motor modules each with three-phase windings are connected to a common shaft. Therefore, using a suitable current control strategy, the motor drive configuration can reduce the torque ripple to the same value as in the healthy operating mode. However, this strategy assumes that the motor windings are designed to be able to handle twice the rated current. The remedial strategy for a switch open-circuit fault in one motor module can be developed by increasing the winding current of the corresponding phase (and during same half cycle) in the second motor module. For example, if $\mathrm{T} 1$ in the motor 1 phase A inverter has an open-circuit fault, this phase can only operate in the negative half cycle of the reference current.

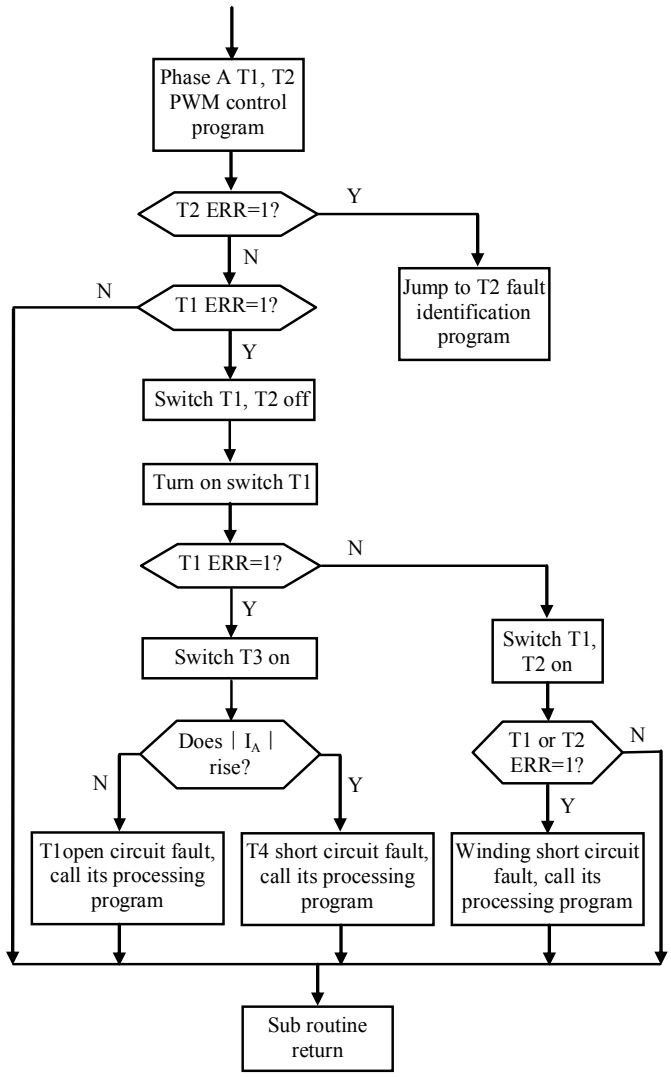

Fig. 8. Fault identification subroutine diagram for a pair of switches in the H-bridge inverter circuit.

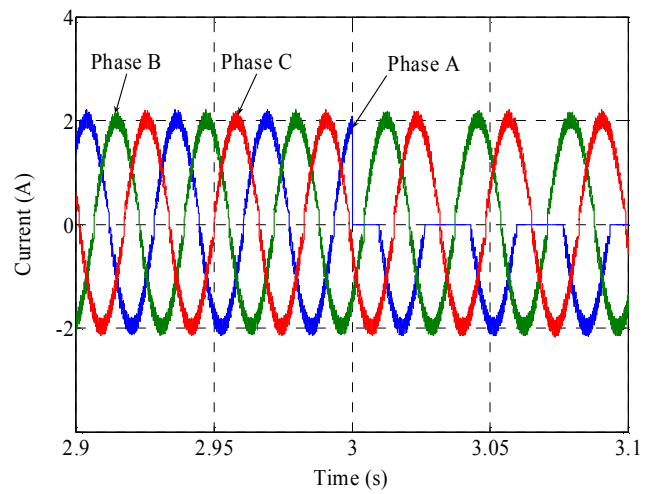

(a) Phase current of motor 1

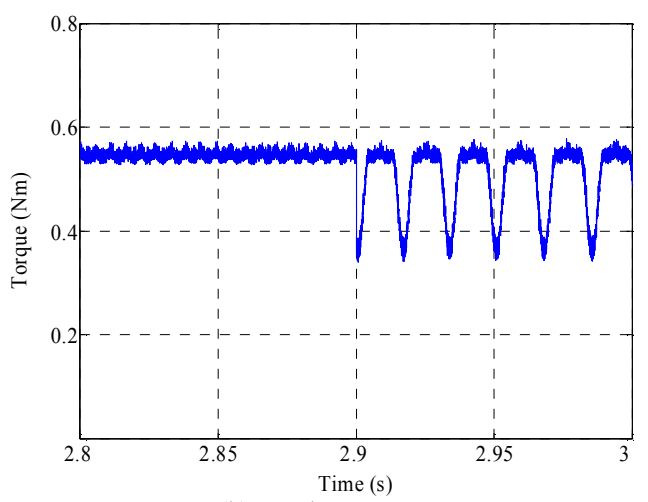

(b) Total output torque

Fig. 9. Simulation results when a switch open-circuit fault occurs at 3.0s in the motor 1 phase A inverter and no remedial strategy adopted after the fault. 
The winding current of the positive half-cycle of phase A in motor module 2 is thus increased (up to twice the rated current) to compensate for the torque loss due to the T1 switch open-circuit fault.

Fig. 10 illustrates the simulation waveforms when switch $\mathrm{T} 1$ in the motor 1 phase A inverter has an open-circuit fault at $\mathrm{t}=3$.0s and the remedial strategy is adopted after the fault. As can be seen in the figure, after the remedial strategy is adopted, the motor drive can generate the same average torque and a similar torque ripple factor as under the healthy state of operation.

\section{B. Remediation of Switch Short-Circuit Faults}

When a switch short-circuit fault occurs in one of the six inverter circuits, this inverter cannot operate in unidirectional conduction mode because it is difficult to control the current in this phase.

A similar fault remedial strategy to that used with the switch open-circuit fault condition is adopted in order to generate rated output torque and reduce the output torque ripple factor. For example, if $\mathrm{T} 3$ in the motor 1 phase $\mathrm{A}$ inverter is short-circuited at 3.0s, the winding current in motor 2 phase $\mathrm{A}$ is doubled at the same time to compensate for the torque loss due to this fault. Fig. 11 describes the simulation results. As can be seen in the figure, after the remedial strategy is adopted, the motor drive can generate the same average torque and a similar torque ripple factor as under the healthy state of operation.

\section{EXPERIMENTAL SETUP}

Fig. 12 and Fig. 13 illustrate the block diagram of the entire drive system and show a photograph of the dual motor module that is coupled to a dynamometer. As shown in Fig. 12, two fault-tolerant three-phase brushless PMAC motor modules are connected on a common shaft with each of the electrically isolated phase windings driven by a separate Hbridge circuit. The two motor modules are also powered from separate power supplies. One inverter board and a separate measurement board (test board) were also implemented for each phase as shown in Fig. 14. As stated previously, this configuration provides a degree of redundancy for the entire drive system.

Two Microchip dsPICDEM MC1 motor control development boards are selected to control the motor modules. The dsPIC30F6010 digital signal controller is installed on the motor control board, which has a 16 channel A/D converter, eight PWM outputs, one encoder input, five 16-bit timers and more than 20 digital input and output ports. The function of the controller includes rotor position measurement, phase current and voltage testing, fault detection and identification and the implementation of the motor control algorithm. The two controllers also communicate with each other to exchange the control and fault information.

\section{CONCLUSIONS}

This paper considered a fault-tolerant motor drive that uses two electrically and magnetically uncoupled three-phase brushless PM motors and individual H-bridge inverters,

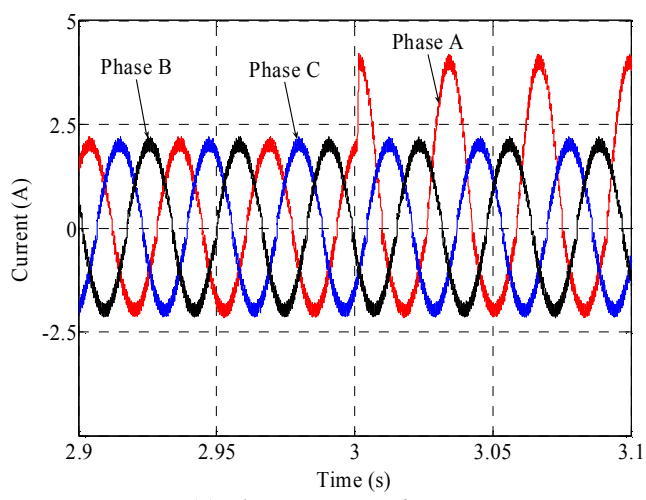

(a) Phase current of motor 2

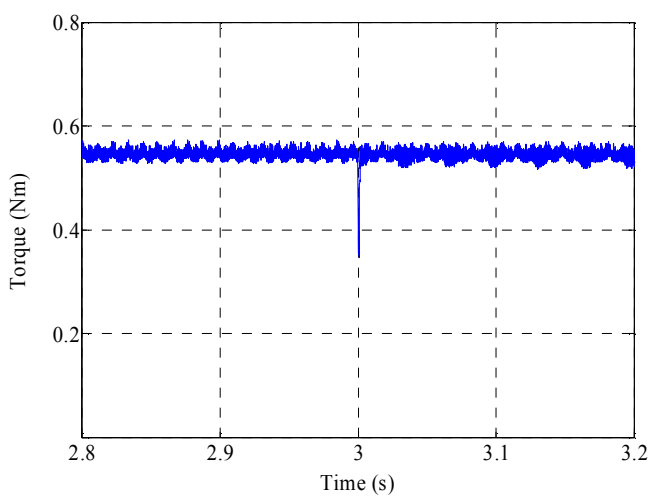

(b) Total output torque

Fig. 10. Simulation results when a switch open-circuit fault occurs at $3.0 \mathrm{~s}$ in the motor 1 phase A inverter and a remedial strategy is adopted after the fault.

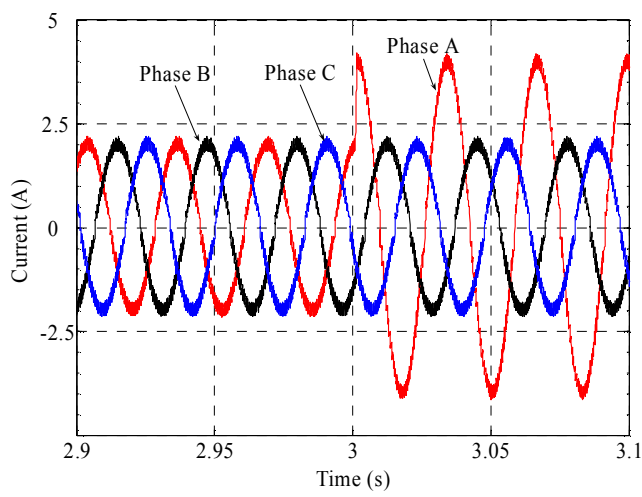

(a) Phase current of motor 2

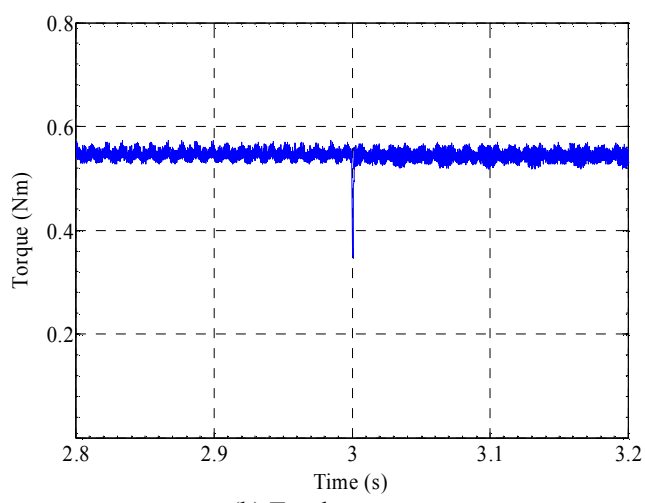

(b) Total output torque

Fig. 11. Simulation results when a switch short-circuit fault occurs at $3.0 \mathrm{~s}$ in the motor 1 phase A inverter and a remedial strategy is adopted after the fault. 
which offer redundancy. The potential faults were analyzed and classified systematically in the paper. The switch fault and winding short-circuit fault detection and identification methods and experimental results were presented. The effects of switch faults on the phase currents and output torque were investigated and some remedial strategies were proposed to compensate for the loss of output torque due to switch faults. It was demonstrated by the simulation studies that after the fault remedial strategy is adopted; the motor drive can provide same output torque and have a similar peak-to peak torque ripple factor as in the healthy operation.

The experimental implementation based on a Microchip dsPIC30F6010 controller was also explained in this paper. The real time behavior of the entire fault-tolerant motor drive with synthetic faults using the hardware developed will be investigated and reported in future studies.

\section{REFERENCES}

[1] C. M. Stephens, "Fault detection and management system for faulttolerant switched reluctance motor drives", IEEE Transactions on Industry Applications, Vol. 27(6), Nov.-Dec. 1991, pp. 1098-1102.

[2] B. C. Mecrow, A. G. Jack, J. A. Haylock, J. Coles, "Fault-tolerant permanent magnet machine drives", IEEE Proceedings-Electric Power Applications, Vol. 143(6), Nov. 1996, pp. 437-442.

[3] J. A. Haylock, B. C. Mecrow, A. G. Jack, and D. J. Atkinson, "Operation of a fault tolerant PM drive for an aerospace fuel pump application", IEEE Proceedings on Electric Power Applications, Vol. 145(5), September 1998, pp. 441-448.

[4] B. C. Mecrow, A. G. Jack, D. J. Atkinson and S. R. Green, "Design and testing of a four-phase fault-tolerant permanent-magnet machine for an engine fuel pump", IEEE Transactions on Energy Conversion, Vol. 19(4), December. 2004, pp. 671-678.

[5] A. G. Jack, B. C. Mecrow, and J. A. Haylock, "A comparative study of permanent magnet and switched reluctance motors for high performance fault-tolerant applications", IEEE Transactions on Industry Applications, Vol. 32(4), July-Aug. 1996, pp. 889-895.

[6] N. Ertugrul, W. Soong, G. Dostal, and D. Saxon, "Fault tolerant motor drive system with redundancy for critical application", IEEE 33rd Power Electronics Specialists Conference, Cairns, Australia, 23-27, June 2002.

[7] J. Zhu, N. Ertugrul, W. Soong, "Performance Investigation of a Fault-Tolerant Brushless Permanent Magnet AC Motor Drive", The CES/IEEE International Power Electronics and Motion Control Conference, Shanghai, China, Aug. 2006.

[8] R. Peuget, S. Courtine, and J. P. Rognon, "Fault detection and isolation on a PWM inverter by knowledge-based model, IEEE Transactions on Industry Applications", Vol. 34, No. 6, Nov./Dec. 1998, pp. 1318-1326

[9] R. L. A. Ribeiro. and C. B. Jacobina, "Fault detection of open-switch damage in voltage-fed PWM motor drive systems, IEEE Transactions on Power Electronics", Vol.18, No.2, March 2003, pp. 587-593.

[10] S. Bolognani, M. Zordan, and M. Zigliotto, "Experimental faulttolerant control of a PMSM drive", IEEE Transactions on Industrial Electronics, Vol. 47(5), Oct. 2000, pp. 1134-1141.
[11] B. G. Park, T. S. Kim, J. S. Ryu anf D. S. Gyun, "Fault Tolerant Strategies for BLDC Motor Drives under Switch Faults", IEEE IAS Annual Meeting, Tampa, Florida, Oct. 2006

[12] H. Z. Huang, Z. G. Tian, and Y. K. Gu, "Reliability and redundancy apportionment optimization using interactive physical programming," International Journal of Reliability, Quality \& Safety Engineering, 2004, Vol. 11, No. 3, pp. 213-222.

[13] J. S. An, N. Ertugrul, and W. Soong, "Sensorless Position Estimation in a Fault Tolerant Surface-Mounted Permanent Magnet AC Motor Drive with Redundancy", IEEE IECON Annual Conference, Paris, Nov. 2006

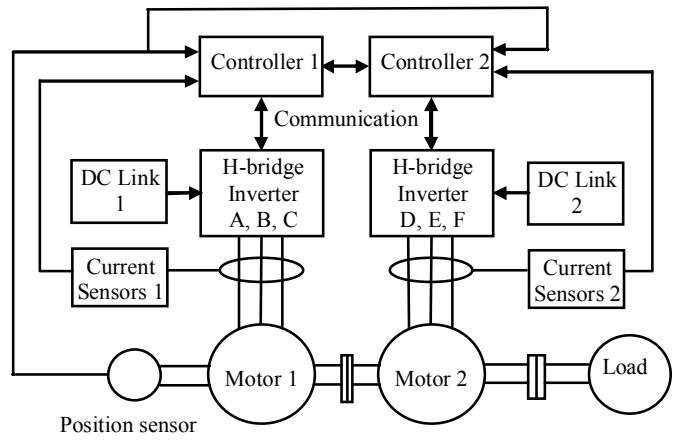

Fig. 12. Motor drive system block diagram

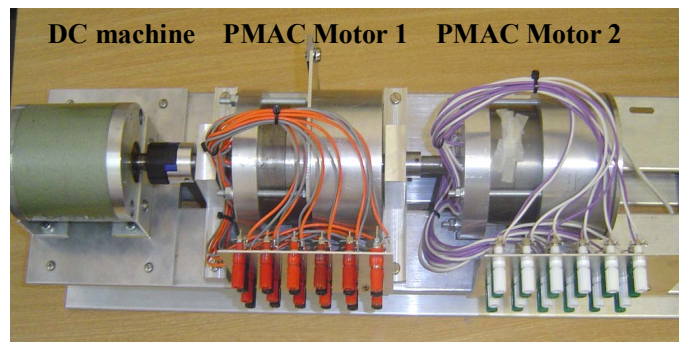

Fig. 13. Photo of the two motor modules and dynamometer setup.

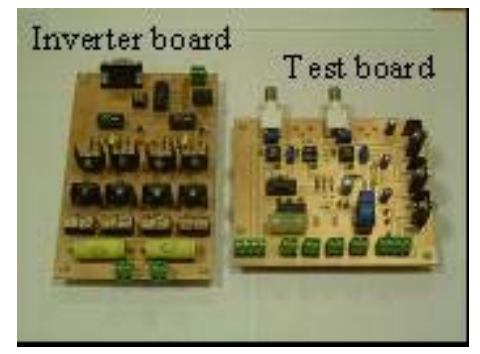

Fig. 14. Photos of an inverter and measurement board for one phase. 